\title{
Depression and associated factors among patients with tuberculosis in Ethiopia: a cross-sectional study
}

This article was published in the following Dove Press journal:

Neuropsychiatric Disease and Treatment

\author{
Alemayehu Molla' \\ Birhanie Mekuriaw' \\ Habtamu Kerebih ${ }^{2}$ \\ 'Department of Psychiatry, College of \\ Medicine and Health Science, Dilla \\ University, Dilla, Ethiopia; ${ }^{2}$ Department \\ of Psychiatry, School of Medicine, College \\ of Medicine and Medical Sciences, \\ University of Gondar, Gondar, Ethiopia
}

Purpose: The study aimed to assess the magnitude of depression and associated factors among patients with tuberculosis (TB) visiting outpatient clinics in Ethiopia.

Patients and methods: A cross-sectional study was conducted among 415 TB patients. Study participants were selected through a systematic random sampling technique. Patient Health Questionnaire-9 (PHQ-9) was used to assess depression using face-to-face interviews. Data were analyzed using SPSS version 20. Bivariate and multivariate binary logistic analyses were done to identify associated factors with depression. $P$-values less than 0.05 were considered statistically significant, and the strength of the association was presented by adjusted OR (AOR) with $95 \%$ CI. Results: The magnitude of depression was found to be $31.1 \%$ with $95 \%$ CI (26.5-35.7). Extrapulmonary TB $[\mathrm{AOR}=1.8,95 \% \mathrm{CI}(1.02,3.24)]$, poor social support $[\mathrm{AOR}=3.3,95 \%$ CI $(1.8,6.03)]$ and perceived TB stigma $[\mathrm{AOR}=2.0,95 \%$ CI $(1.28,3.18)]$ were variables found to be statistically significantly connected with depression.

Conclusion: The magnitude of depression was high compared to the general population and some other studies. Therefore, the current study area and other settings which provide TB screening and treatment need to assess patients for depression and provide intervention, giving more emphasis to patients with risk factors.

Keywords: depressive illness, outpatient clinics, tuberculosis patients

\section{Introduction}

Tuberculosis (TB) is a chronic infectious disease caused by bacteria (Mycobacterium tuberculosis) and commonly affects the lung. ${ }^{1}$ It is a public health concern due to its high morbidity and mortality throughout the world in all population groups. ${ }^{2}$ Although all age groups are at risk to develop TB, it affects adults in their most productive years and over $95 \%$ of cases and deaths are in developing countries like Ethiopia. ${ }^{3}$ Moreover, Multidrug-resistant TB (MDR-TB) is also a major public health crisis and a health security threat currently worsening in developing countries. ${ }^{4}$ In addition to its biological deteriorative impact, TB causes social, psychological and economic problems for the individuals, families, and community as a large, and it has a bimodal relationship with depression.,6

Mental illness comprised about $13 \%$ of the total global burden of disease and is expected to rise to $15 \%$ by the year $2020 .^{7,8}$ Among the psychiatric problems, depression is the fourth leading cause of disease burden worldwide; representing $4.5 \%$ of total disability-adjusted life years. Depression is predicted to become the second leading cause of the global disease burden by the year 2020., ${ }^{7-11}$ The disability associated with depression in relation to chronic medical disease is high, where people are already struggling for survival and the catastrophic impact of a
Correspondence: Alemayehu Molla Department of Psychiatry, College of Medicine and Health Science, Dilla University, Dilla 419, Ethiopia Email alexmolla09@gmail.com 
chronic and disabling illness. ${ }^{12}$ Furthermore, depression hinders good treatment outcome, and it can cause disability and poor quality of life. ${ }^{13}$

Some studies showed that the prevalence of depression among patients with TB is higher than in the general population. A study from South Africa showed the prevalence of depression was $32.9 \% .{ }^{14}$ In Nigeria depression was reported as $27.7 \%$ and $45.5 \%,{ }^{15,16}$ and in Ethiopia, $54.0 \%$ of TB patients were reported to have depression. ${ }^{3}$ Older age, level of education, social supports, female sex, perceived TB stigma and duration of illness were some factors identified as being associated with depression., ${ }^{3,14-17}$

Overall, different psychosocial problems like depression and other mild and moderate psychiatric features are very common among patients with TB. Even though some studies are available with regard to depression related to TB in Ethiopia, still little attention was given to consider depression among patients with TB. The aim of this study was to determine the magnitude of depression and associated factors among patients with TB.

\section{Patients and methods}

An institution based cross-sectional study was conducted at Saint Peter's specialized hospital, which is a federal hospital located in Gulele subcity in Addis Ababa, Ethiopia. Patients aged 15 and above visiting an outpatient TB clinic were included in the study. Ethical clearance was obtained from the University of Gondar and Amanuel Mental Specialized Hospital Institutional Review Board (IRB). Identification or name of participants was not recorded to maintain confidentiality. Data were collected after obtaining written informed consent from participants and caregivers were required to provide consent for participants under the age of 18 years.

The sample size was determined using a single population proportion formula with a confidence interval of $95 \%$, $\alpha=0.05$, and $P=50 \%$. Proportional allocation was done for non-MDR-TB patients and MDR-TB patients using data from the registration book, and participants from both types were selected through a systematic random sampling technique. Finally, 415 (308, from non-MDR-TB and 107 from MDR-TB) patients were interviewed during data collection.

The questionnaire has four components: sociodemographic characteristics, clinically related factors, Oslo social support scale, patient health questionnaire (PHQ-9) and perceived TB stigma scale.

Outcome variables were assessed using PHQ-9 questionnaires which have 9 items, and each item has a 4-point Likert scale $(0=$ not at all to $3=$ nearly every day $)$.
Individuals who score 10 and above were considered as having depression. ${ }^{18}$ The PHQ-9 has been previously used in Ethiopia in other studies. ${ }^{19,20}$ PHQ-9 is also culturally validated in the Ethiopian context with specificity and sensitivity of $67 \%$ and $86 \%$, respectively. ${ }^{18}$

Social support was assessed by a 3-item Oslo social support scale, which ranges from 3 to 14 . Oslo-3 has three categories: score of 3-8 is poor support, 9-11 moderate support and 12-14 strong support. ${ }^{21}$

TB stigma was assessed using a 12 -item perceived TB stigma scale. This stigma scale consists of a 4-point Likert scale and item scores of the stigma questions were summed to construct a single stigma variable. Respondents were classified as having or not having perceived TB stigma using the mean of the stigma scale as a cutoff point. ${ }^{22}$

Data were collected by two psychiatric nurses using pre-tested face-to-face interviewer-administered questionnaires. To control the quality of data the questionnaire was designed, modified appropriately and was translated to the local language (Amharic) to be understood by all participants and translated back to English. Training was provided to data collectors and supervisors for two days on methodology, ethical concern and how to supervise the data collection process. The questionnaire was pretested and data collectors were supervised, and the filled questionnaires were checked daily.

Data were entered to Epi-data version 3.1 and exported to SPSS version 20 (IBM Coproration, Armonk, NY, USA) for further analysis. Bivariate analysis was done to see the association of each independent variable with the outcome variable. Finally, from multivariate analysis, a $p$-value less than 0.05 was considered statistically significant, and adjusted OR with $95 \% \mathrm{CI}$ was used to determine association.

\section{Results \\ Sociodemographic distribution of the participants}

About 415 participants were included in the study, and the response rate was $98.1 \%$. The age range of the participants was $15-78$ years with a mean age of $34.56( \pm 12.6)$. Over half (222; 53.5\%) were male. Among participants, 161 (38.8\%) were orthodox religion followers and 134 (32.3\%) were Amhara in their ethnicity. Regarding the educational status of participants, 118 (28.4\%) of them had a primary level of education. The majority of respondents were from urban areas $(328 ; 79 \%)$. The monthly income of respondents ranged from 100 to 5,000 Ethiopian birr (Table 1). 
Table I Sociodemographic distributions of TB patients attending outpatient treatment at Saint Peter's Specialized Hospital, Addis Ababa, Ethiopia, 2018

\begin{tabular}{|c|c|c|}
\hline Variable & Frequency $(N=4 \mid 5)$ & Percent (\%) \\
\hline \multicolumn{3}{|l|}{ Age } \\
\hline $15-24$ & 96 & 23.1 \\
\hline $25-34$ & 140 & 33.74 \\
\hline $35-44$ & 83 & 20 \\
\hline $45-54$ & 61 & 14.7 \\
\hline$>54$ & 35 & 8.4 \\
\hline \multicolumn{3}{|l|}{ Sex } \\
\hline Female & 193 & 46.5 \\
\hline Male & 222 & 53.5 \\
\hline \multicolumn{3}{|l|}{ Religion } \\
\hline Orthodox & 162 & 39 \\
\hline Protestants & 95 & 22.9 \\
\hline Muslim & 116 & 28 \\
\hline Catholic & 29 & 7 \\
\hline Others* & 13 & 3.1 \\
\hline \multicolumn{3}{|l|}{ Marital status } \\
\hline Single & 140 & 33.7 \\
\hline Married & 176 & 42.4 \\
\hline Divorced & 54 & 13 \\
\hline Widowed & 45 & 10.8 \\
\hline \multicolumn{3}{|l|}{ Ethnicity } \\
\hline Amhara & 134 & 32.3 \\
\hline Tigre & 91 & 21.9 \\
\hline Oromo & 117 & 28.2 \\
\hline Gurage & 56 & 13.5 \\
\hline Others** & 17 & 4.1 \\
\hline \multicolumn{3}{|l|}{ Education level } \\
\hline Have no formal education & 79 & 19 \\
\hline Primary & 118 & 28.4 \\
\hline Secondary & 94 & 22.7 \\
\hline Preparatory & 63 & 15.2 \\
\hline College and above & 61 & 14.7 \\
\hline \multicolumn{3}{|l|}{ Occupational status } \\
\hline Trading & 97 & 23.4 \\
\hline Farming & 101 & 24.34 \\
\hline Government employee & 135 & 32.52 \\
\hline Private employee & 62 & 14.94 \\
\hline Others*** & 20 & 4.82 \\
\hline \multicolumn{3}{|l|}{ Residency } \\
\hline rural & 87 & 21 \\
\hline Urban & 328 & 79 \\
\hline \multicolumn{3}{|l|}{ Monthly income } \\
\hline$<1,539$ ETB & 246 & 59.3 \\
\hline$\geq 1,539$ ETB & 169 & 40.7 \\
\hline
\end{tabular}

Notes: Others *Jehovah's Witnesses and have no religion; **Wolyita and Silite; ***H House wife and students.

Abbreviations: TB, tuberculosis; ETB, Ethiopian Birr.

\section{Clinical and psychosocial factors of the respondents}

The majority of respondents had a diagnosis of pulmonary TB (344; 83\%) and 257 (61.9\%) of participants were in the new TB treatment category. Two-thirds of the participants were in the intensive phase of treatment (277; $65.5 \%$ ). Among psychosocial factors poor social support and perceived TB stigma were reported by 177 (42.7\%) and 187 (45.1\%) of participants, respectively. Among study participants, 40 (9.6\%) had comorbid HIV illness (Table 2).

Table 2 Clinical and psychosocial factors of TB patients attending outpatient treatment at Saint Peter's Specialized Hospital, Addis Ababa, Ethiopia, 2018

\begin{tabular}{|c|c|c|}
\hline Variables & Frequency & Percent (\%) \\
\hline \multicolumn{3}{|l|}{ TB site } \\
\hline Extrapulmonary & 71 & 17 \\
\hline Pulmonary & 344 & 83 \\
\hline \multicolumn{3}{|l|}{ Duration of illness } \\
\hline$<6$ months & 166 & 40 \\
\hline $6-12$ months & 185 & 44.6 \\
\hline$>12$ months & 64 & 15.4 \\
\hline \multicolumn{3}{|l|}{ TB treatment category } \\
\hline New & 257 & 61.9 \\
\hline Re-treatment & 53 & 12.8 \\
\hline MDR-TB & 105 & 25.3 \\
\hline \multicolumn{3}{|l|}{ Phase of treatment } \\
\hline Continuation phase & 143 & 34.5 \\
\hline Intensive phase & 272 & 65.5 \\
\hline \multicolumn{3}{|l|}{ Physical illness } \\
\hline HIV & 40 & 9.6 \\
\hline Other chronic illness & 33 & 8 \\
\hline No & 342 & 82.4 \\
\hline \multicolumn{3}{|l|}{ Family $\mathrm{Hx}$ of mental illness } \\
\hline No & 362 & 87.2 \\
\hline Yes & 53 & 12.8 \\
\hline \multicolumn{3}{|l|}{ Social support } \\
\hline Poor & 177 & 42.7 \\
\hline Moderate & 121 & 29.4 \\
\hline Strong & 117 & 28 \\
\hline \multicolumn{3}{|l|}{ Perceived TB stigma } \\
\hline No & 228 & 54.9 \\
\hline Yes & 187 & 45.1 \\
\hline
\end{tabular}

Notes: Other chronic illnesses include hypertension, diabetics, and cardiac diseases.

Abbreviations: TB, tuberculosis; MDR-TB, multidrug-resistant tuberculosis; $\mathrm{Hx}$, history. 


\section{Current substance use characteristics of respondents}

Thirty-one $(7.5 \%)$ of respondents reported that they had used alcohol, 12 (2.9\%) had smoked cigarettes and 17 (4.1\%) had chewed khat in the three months before data collection (Table 3).

\section{Prevalence depression among patients with tuberculosis}

The prevalence of depression among patients with TB was $31.1 \%$ with $95 \%$ CI (26.5-35.7). Among respondents with depression, 66 (51.2\%) were female and 95 (73.64\%) of depressed participants had a diagnosis of pulmonary TB. Regarding the treatment category of TB, 75 (58.14\%) of respondents were in the new treatment category, 41 (31.8\%) were in the MDR-TB treatment category. Sixtyfour $(49.6 \%)$ of participants with depression had poor social support and 75 (58.12\%) reported perceived stigma related to TB (see Figure S1).

\section{Factors associated with depression among patients with tuberculosis}

In bivariate binary logistic analysis variables, being female, having extrapulmonary TB, duration of TB illness $>12$ months, treatment category of MDR-TB, comorbid HIV illness, poor social support and perceived TB stigma were found to have $P$-values less than 0.25 . These variables fulfilled the minimum requirements for further multivariate binary logistic regression.

From multivariate binary logistic regression variables; extrapulmonary TB $1.8(95 \% \mathrm{CI}, 1.02,3.24)$ poor social

Table 3 Current substance use characteristics of participants with tuberculosis visiting outpatient clinics at Saint Peter's Specialized Hospital, Addis Ababa, Ethiopia, 2018

\begin{tabular}{|l|l|l|}
\hline Variables & Frequency & Percent (\%) \\
\hline $\begin{array}{l}\text { Current alcohol use } \\
\text { Yes }\end{array}$ & 31 & \\
No & 384 & 7.5 \\
\hline $\begin{array}{l}\text { Current cigarette use } \\
\text { Yes }\end{array}$ & 12 & 92.5 \\
No & 403 & \\
\hline Current khat use & & 2.9 \\
Yes & 17 & 97.1 \\
No & 398 & 4.1 \\
\hline
\end{tabular}

support 3.3 (95\% CI, 1.8, 6.03), and perceived TB stigma $2(95 \% \mathrm{CI}, 1.28,3.18)$ were statistically significant with depression at $P$-value less than 0.05 (see Table 4).

\section{Discussions}

The magnitude of depression in the current study was $31.1 \%$ with $95 \%$ CI (26.5-35.7). Regarding the magnitude, the finding was similar to studies carried out in Nigeria $27.7 \%,{ }^{15}$ South Africa $32.9 \%{ }^{14}$ and India $35 \% .{ }^{23}$

The finding of the current study was lower than studies done in India $(39.5 \%),{ }^{24}$ Greece $(49.2 \%),{ }^{25}$ Ethiopia $(43.3 \%),{ }^{17}$ Nigeria $(45.5 \%, 41.9 \%),{ }^{16,26}$ Pakistan $(69.55 \%$, $46.5 \%),{ }^{4,27}$ and Tanzania (46.9\%). ${ }^{28}$ The possible reason for the discrepancy might be variation in study design and sample size used. The study conducted in India used a consecutive sampling technique, and the Beck Depression iInventory was the tool they used to assess depression. The difference in study design might be another possible reason for the variation, as an ongoing prospective study was used in Nigeria. ${ }^{16}$ Another possible reason might be socioeconomic, cultural and sample size differences between the previous and the current studies.

However, the finding was higher than other studies conducted in India $(22 \%),{ }^{29}$ and UK $(20.8 \%){ }^{30}$ The variation might be due to the difference in study design; the Indian study was a retrospective study from medical records, and hospital anxiety and depression (HADS depression D) was used to assess depression. A difference in study participants might be another possible reason for the variation. Participants form continuation phase of TB treatment in previous study might have improvement due to better duration of treatment contact with professional and their interaction could minimize their depressive feeling. ${ }^{31}$

Participants with poor social support were 3.3 times more likely to have depression as compared with participants with good social support. This is supported by study results from Pakistan (46.5\%), ${ }^{27}$ Ethiopia (43.4\%) ${ }^{17}$ and India (39.5\%). ${ }^{24}$ This might be due to a lack of social support, and somatic illness (TB) may lead to increased psychological distress (mental disorders); on the other hand, good social support is vital for good disease prevention. ${ }^{32}$

Diagnosis of extrapulmonary TB was another factor associated with depression; patients with extrapulmonary TB were about 1.8 times more likely to be depressed as compared with their counterparts. This is in agreement with a study from Nigeria. ${ }^{16}$ This could be due to extrapulmonary TB having a poorer prognosis than pulmonary TB, which might lead patients to be depressed more. 
Table 4 Logistic regression analysis of factors associated with depression among patients with tuberculosis visiting outpatient clinics at Saint Peters Hospital, Addis Ababa Ethiopia, 2018 (N=415)

\begin{tabular}{|c|c|c|c|c|}
\hline \multirow[t]{2}{*}{ Explanatory variables } & \multicolumn{2}{|c|}{ Depression } & \multirow[t]{2}{*}{ COR $(95 \% \mathrm{Cl})$} & \multirow[t]{2}{*}{ AOR (95\% Cl) } \\
\hline & Yes (N) & No & & \\
\hline \multicolumn{5}{|l|}{ Sex } \\
\hline Male & 63 & 159 & 1 & I \\
\hline Female & 66 & 127 & $1.31(0.86,1.99)$ & $1.03(0.65,1.65)$ \\
\hline \multicolumn{5}{|l|}{ Site of TB } \\
\hline Pulmonary & 95 & 249 & 1 & 1 \\
\hline Extrapulmonary & 34 & 37 & $2.41(1.43,4.1)$ & $1.8(1.02,3.24)$ \\
\hline \multicolumn{5}{|l|}{ Category of TB Rx } \\
\hline New & 75 & 185 & 1 & 1 \\
\hline MDR & 41 & 66 & $1.53(0.96,2.46)$ & $1.32(0.77,2.24)$ \\
\hline Re-treatment & 13 & 35 & $0.92(0.46,1.83)$ & $0.97(0.45,2.1)$ \\
\hline \multicolumn{5}{|l|}{ Medical illness } \\
\hline HIV & 21 & 19 & $2.83(1.46,5.5)$ & $1.93(0.94,3.93)$ \\
\hline Others* & 12 & 21 & $1.46(0.69,3.1)$ & $\mathrm{I} .4 \mathrm{I}(0.62,3.2)$ \\
\hline No & 96 & 246 & 1 & I \\
\hline \multicolumn{5}{|l|}{ Social support } \\
\hline Poor & 84 & 93 & $2.04(I .2 I, 3.44)$ & $3.3(1.8,6.03)$ \\
\hline Moderate & 24 & 97 & $1.02(0.57,1.85)$ & $1.04(0.53,2.06)$ \\
\hline Strong & 21 & 96 & I & I \\
\hline \multicolumn{5}{|l|}{ Perceived TB stigma } \\
\hline Yes & 79 & 108 & $2.6(1.7,4)$ & $2(1.28,3.18)$ \\
\hline No & 50 & 178 & 1 & I \\
\hline \multicolumn{5}{|l|}{ Duration of illness } \\
\hline$<6$ months & 53 & 114 & 1 & 1 \\
\hline 6-12 months & 51 & 133 & $0.83(0.52,1.3)$ & $0.6(0.36,1.01)$ \\
\hline$>12$ months & 25 & 39 & $\mathrm{I} .4(0.76,2.5 \mathrm{I})$ & $1.19(0.61,2.34)$ \\
\hline
\end{tabular}

Notes: Chi-square $=1.8, \mathrm{df}=8$, Hosmer Lemeshow test $p$-value $=0.32$. ${ }^{\circ}$ Others include hypertension, diabetics, cardiac diseases. The significance of values in bold is to recognize and identify associated factors easily.

Abbreviations: COR, crude odds ratio; AOR, adjusted odds ratio; TB, tuberculosis; Rx, treatment; MDR, multidrug resistance.

The study revealed that perceived TB stigma was also associated with depression; patients with perceived TB stigma were 2 times more likely to have depression. This is in line with studies conducted in Pakistan $(46.5 \%)^{27}$ and Ethiopia (43.3\%). ${ }^{17}$ Patients with perceived TB stigma might use health services less due to low self-esteem, and social isolation, and as a result, this might predispose them to developing depression.

While there are important findings in the current study, care should be taken in interpreting the results due to the following limitations. Side effects of the anti-TB medication were not addressed. Since the entire sample was taken from a single hospital in the capital city, the findings of this study might not be generalized to other areas, especially in rural settings.

\section{Conclusions}

The magnitude of depression was high compared to the general population and some other studies. Therefore, the current study area and other settings which provide TB screening and treatment need to assess patients for depression and provide intervention, giving more emphasis to patients with risk factors. Additionally, further research using different study designs on risk factors of depression like TB medication side effects should be conducted to broaden the current findings.

\section{Acknowledgments}

The authors acknowledge the College of Medicine and Health Sciences, University of Gondar and Amanuel Specialized Mental Health Hospital for their financial 
and technical support for data collection. The authors are also very grateful to Saint Peter's Specialized Hospital TB clinical staff, data collectors, and all the study participants involved in the study.

\section{Author contributions}

All authors contributed towards data analysis, drafting and critically revising the paper, gave final approval of the version to be published, and agreed to be accountable for the all aspects of the work.

\section{Disclosure}

The authors declare that they have no conflicts of interest in this work.

\section{References}

1. Zaman K. Tuberculosis: a global health problem. J Health Popul Nutr. 2010;28(2):111. doi:10.3329/jhpn.v28i2.4879

2. Sulehri MA, Dogar IA, Sohail H, et al. Prevalence of depression among tuberculosis patients. Paper presented at: APMC; Faisalabad, Pakistan; 2010.

3. Ambaw F, Mayston R, Hanlon C, Alem A. Burden and presentation of depression among newly diagnosed individuals with TB in primary care settings in Ethiopia. BMC Psychiatry. 2017;17(1):57. doi:10.1186/s12888-017-1489-6

4. Javaid A, Mehreen S, Khan M, Ashiq N, Ihtesham M. Depression and its associated factors with multidrug-resistant tuberculosis at baseline. J Depress Anxiety. 2017;6(253):2167-1044.1000253. doi:10.4172/2167-1044.1000253

5. Oh K, Choi H, Kim E, Kim H, Cho S. Depression and risk of tuberculosis: a nationwide population-based cohort study. Int J Tuberculosis Lung Dis. 2017;21(7):804-809. doi:10.5588/ijtld.17.0038

6. Koyanagi A, Vancampfort D, Carvalho AF, et al. Depression comorbid with tuberculosis and its impact on health status: cross-sectional analysis of community-based data from 48 low-and middle-income countries. BMC Med. 2017;15(1):209. doi:10.1186/s12916-017-0975-5

7. Reddy M. Depression: the disorder and the burden. Indian J Psychol Med. 2010;32(1):1. doi:10.4103/0253-7176.70510

8. Vigo D, Thornicroft G, Atun R. Estimating the true global burden of mental illness. Lancet Psychiatry. 2016;3(2):171-178. doi:10.1016/ S2215-0366(15)00505-2

9. Chisholm D, Flisher A, Lund C, et al. Scale up services for mental disorders: a call for action. Lancet. 2007;370(9594):1241-1252.

10. Miranda JJ, Patel V. Achieving the millennium development goals: does mental health play a role? PLoS Med. 2005;2(10):e291. doi:10.1371/journal.pmed.0020291

11. Michaud CM, Murray CJ, Bloom BR. Burden of disease-implications for future research. Jama. 2001;285(5):535-539.

12. Katon W, Sullivan MD. Depression and chronic medical illness. $J$ Clin Psychiatry. 1990;51(Suppl 6):3-11.

13. Ambaw F, Mayston R, Hanlon C, Medhin G, Alem A. Untreated depression and tuberculosis treatment outcomes, quality of life and disability, Ethiopia. Bull World Health Organ. 2018;96(4):243. doi:10.2471/BLT.17.206417

14. Peltzer K, Naidoo P, Matseke G, Louw J, Mchunu G, Tutshana B. Prevalence of psychological distress and associated factors in tuberculosis patients in public primary care clinics in South Africa. BMC Psychiatry. 2012;12(1):89. doi:10.1186/1471-244X-12-86
15. Issa BA, Yussuf AD, Kuranga SI. Depression comorbidity among patients with tuberculosis in a university teaching hospital outpatient clinic in Nigeria. Ment Health Fam Med. 2009;6(3):133.

16. Ige OM, Lasebikan VO. Prevalence of depression in tuberculosis patients in comparison with non-tuberculosis family contacts visiting the DOTS clinic in a Nigerian tertiary care hospital and its correlation with disease pattern. Ment Health Fam Med. 2011;8(4):235.

17. Duko B, Gebeyehu A, Ayano G. Prevalence and correlates of depression and anxiety among patients with tuberculosis at WolaitaSodo University Hospital and Sodo Health Center, WolaitaSodo, South Ethiopia, Cross sectional study. BMC Psychiatry. 2015;15(1):214. doi:10.1186/s12888-015-0598-3

18. Gelaye B, Williams MA, Lemma S, et al. Validity of the patient health questionnaire-9 for depression screening and diagnosis in East Africa. Psychiatry Res. 2013;210(2):653-661. doi:10.1016/j. psychres.2013.07.015

19. Bitew H, Andargie G, Tadesse A, Belete A, Fekadu W, Mekonen T. Suicidal ideation, attempt, and determining factors among HIV/AIDS patients, Ethiopia. Depress Res Treat. 2016;2016.

20. Molla A, Mengesha A, Derjaew H, Kerebih H. Suicidal ideation, attempt, and associated factors among patients with tuberculosis in Ethiopia: a cross-sectional study. Psychiatry J. 2019;2019.

21. Dalgard OS, Dowrick C, Lehtinen V, et al. Negative life events, social support and gender difference in depression. Soc Psychiatry Psychiatr Epidemiol. 2006;41(6):444 451. doi:10.1007/s00127-006-0051-5

22. Van Rie A, Sengupta S, Pungrassami P, et al. Measuring stigma associated with tuberculosis and HIV/AIDS in southern Thailand: exploratory and confirmatory factor analyses of two new scales. Trop Med Int Health. 2008;13(1):21-30. doi:10.1111/j.13653156.2007.01971.x

23. Kumar K, Kumar A, Chandra P, Kansal HM. A study of prevalence of depression and anxiety in patients suffering from tuberculosis. J Family Med Primary Care. 2016;5(1):150. doi:10.4103/2249-4863.184641

24. Balaji AL, Abhishekh HA, Kumar NC, Mehta RM. Depression in patients with pulmonary tuberculosis in a tertiary care general hospital. Asian $J$ Psychiatr. 2013;6(3):251-252. doi:10.1016/j.ajp.2012.12.017

25. Moussas G, Tselebis A, Karkanias A, et al. A comparative study of anxiety and depression in patients with bronchial asthma, chronic obstructive pulmonary disease and tuberculosis in a general hospital of chest diseases. Ann Gen Psychiatry. 2008;7(1):7. doi:10.1186/1744-859X-7-7

26. Aniebue P, Okonkwo K. Prevalence of depressive symptoms amongst pulmonary tuberculosis patients at the University of Nigeria Teaching Hospital, Enugu. Int J Med Health Dev. 2006;11(2):120-124.

27. Husain MO, Dearman SP, Chaudhry IB, Rizvi N, Waheed W. The relationship between anxiety, depression and illness perception in tberculosis patients in Pakistan. Clin Pract Epidemiol Mental Health. 2008;4(1):4. doi:10.1186/1745-0179-4-4

28. Buberwa G. Prevalence of Depression among Tuberculosis Patients Attending Clinics in Temeke Municipal, Dar Es Salaam. Tanzania: Muhimbili University of Health and Allied Sciences; 2013.

29. Francis D. Prevalence of depression among patients with tuberculosis at Perundurai TB hospital, Tamilnadu-depression, a comorbidity of TB. Eur Psychiatry. 2017;41:S472. doi:10.1016/j. eurpsy.2017.01.541

30. Cleland JA, Lee AJ, Hall S. Associations of depression and anxiety with gender, age, health-related quality of life and symptoms in primary care COPD patients. Fam Pract. 2007;24(3):217-223. doi:10.1093/fampra/cmm009

31. Nezenega ZS, Tafere TE. Patient satisfaction on tuberculosis treatment service and adherence to treatment in public health facilities of Sidama zone, South Ethiopia. BMC Health Serv Res. 2013;13(1):110. doi:10.1186/1472-6963-13-438

32. Bøen H, Dalgard OS, Johansen R, Nord E. Socio-demographic, psychosocial and health characteristics of Norwegian senior centre users: a cross-sectional study. Scand J Public Health. 2010;38 (5):508-517. doi:10.1177/1403494810370230 


\section{Supplementary material}

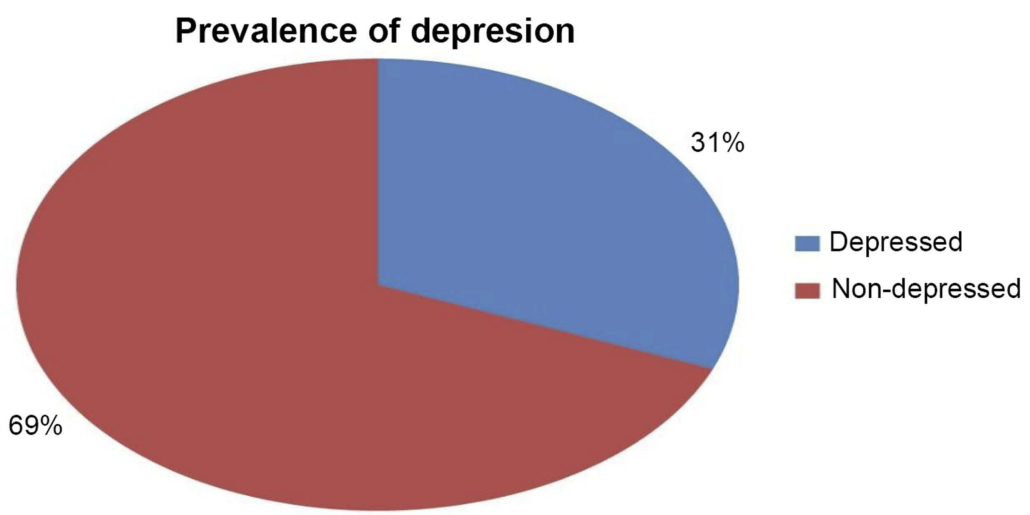

Figure SI Magnitude of depression among patients with tuberculosis visiting outpatient clinics at Saint Peter's Specialized Hospital, Addis Ababa, Ethiopia.

\section{Publish your work in this journal}

Neuropsychiatric Disease and Treatment is an international, peerreviewed journal of clinical therapeutics and pharmacology focusing on concise rapid reporting of clinical or pre-clinical studies on a range of neuropsychiatric and neurological disorders. This journal is indexed on PubMed Central, the 'PsycINFO' database and CAS, and is the official journal of The International Neuropsychiatric Association (INA). The manuscript management system is completely online and includes a very quick and fair peer-review system, which is all easy to use. Visit http://www.dovepress.com/testimonials.php to read real quotes from published authors. 